\title{
The Reasonable Application of Digital Media Technology on Museum Display
}

\author{
Zhijian Wang \\ Changzhou Vocational Institue of Engineering, Changzhou, China
}

Keywords: Digital media, Museum display, Application study

\begin{abstract}
In recent years, digital media technology has been widely used in the field of museum display. It has played an important role in enhancing display performance, enriching the audience experience, enhancing information dissemination and communication, and increasing the vividness, fun, participation and interaction of display. effect. At the same time, the phenomenon of abuse and misuse is unchecked, which affects the scientific nature of museum display and is not conducive to the effective display of functions.
\end{abstract}

\section{Introduction}

In recent years, digital media technology has played a very important role in museum exhibitions, such as digital audio navigation, interactive information systems, digital audio-visual, virtual reality and other technologies have become a common means of museum display. According to statistics, in the new museum exhibitions (except the Science and Technology Museum) in recent years, the actual investment in digital media exhibitions is about $15 \%$ to $25 \%$ of the total investment. However, in the museum industry, there are major differences in how digital media technology is used and to what extent. The actual display effect of a large number of digital media exhibits that have been put into use is often unsatisfactory. The main reason is that the museum's display designers and digital media designers lack understanding between each other. The former is not aware of the conditions and production requirements for technology implementation. The effect, the latter is not familiar with the characteristics of the museum display and the purpose of the communication that needs to be achieved. Therefore, it has caused the current situation that the overall museum display is divided into two parts: traditional media and digital media. It is in the planning and design construction. For example, in the display design, the digital media exhibition is usually displayed by the general contractor. Subcontracting to professional digital media production companies, neglecting the control and coordination of the exhibitions, seriously undermined the overall effect of the museum display, not only caused the waste of public cultural resources, but also was not conducive to the full play of the museum's social functions.

\section{Characteristics and Advantages of Digital Media}

The use of digital media allows viewers to view content in a versatile, multi-angle manner. For the display of three-dimensional objects, each side of the object can be displayed by rotation, or the internal, usually invisible parts can be displayed by changing the angle of view. For example, the bronze statue of the bronze statue of the Capital Museum uses a three-dimensional model map method, allowing the viewer to operate to rotate the angle of the view and see the various sides of the Buddha image. In addition, visual 3D technology can also be used to enhance the audience's experience. In addition, the three-dimensional holographic projection can display dynamic three-dimensional objects in space, giving the audience an intuitive feeling. The use of digital media technology to restore the original appearance of the damaged cultural relics, so that the audience can fully and comprehensively understand the display content. For example, the ruins of the Yuanmingyuan in Beijing have experienced the ravages of war. At present, there is only a small amount of building foundation left. It is not the same as the imposing and beautiful royal gardens at that time. As a result, in recent years, various people have proposed to rebuild the Yuanmingyuan. The motion " 1 . However, according to the principle of ancient site protection, large-scale "repair" 
and "reconstruction" are the destruction of the original authenticity of the site, and the existing archives are difficult to restore its original appearance. Under current conditions, Using AR technology to combine the existing architectural relics with the digital virtual original features, it can not destroy the ancient sites, but also completely display the original appearance of the site. A similar case is the ancient ship of the Chinese Ancient Ship Museum (under construction). The restoration of the wreckage and the digital restoration of the ancient Roman city.

Through digital media technology, virtual deconstruction of large-scale cultural relics, enlargement of close-up parts of cultural relics exhibits, high-definition display of fine features such as strokes and seals of paintings and calligraphy, so that the audience can clearly see the details of the texture, depiction and engraving of the exhibits. It can better compensate for the inconvenience of physical display, close observation, insufficient lighting in the exhibition hall, and lack of sufficient details. For example, the paintings and paintings on the website of the Palace Museum show the high-definition scanned paintings and paintings to the audience through the network. You can arbitrarily enlarge the designated parts of the exhibits, not only can display the original appearance of the paintings 1:1, but also zoom in and out several times. Far better than the physical display in the exhibition hall, it can be said that the contradiction between cultural relic protection and display is well solved.

Compared with the traditional display of single visual communication, digital media technology can convey richer display information through other senses such as hearing, touch, and sense of sight. The display is no longer limited to "look", but a display that can be seen, audible, touchable and sensible. For example, digital audio can be used to convey auditory information such as dialects, operas, songs, and tones.

Digital media technology is used to express dynamic processes with obvious and intuitive features. For example, the display of the craft process, relying on cultural relics and plates, the model is difficult to clearly express the manufacturing process, and the use of digital media images or three-dimensional animation can better achieve the purpose of communication, so that the audience can be seen. Another example is the display of some dynamic diachronic processes (ecological changes, urban changes) that can be better represented through digital media technologies. For example, the China Wetland Museum's demonstration of the natural ecological changes in Xixi, Daqing Oilfield History Exhibition Hall's Daqing City Change Exhibition shows the historical process of the rapid development of Daqing, a city born of oil, in a few decades. Another example is the event of the Huanggutun incident at the Museum of History of the Eighty-eighth Eighth. It is necessary to express the entire process of Zhang Zuolin's special event through the railway interchange--the command of the Japanese military officer--the train blown up. It is better to use the digital media image combined with the simulation scene. The relationship between the two parties in the event and the entire event process.

\section{Digital Media in the Display Application Problems}

At present, there are trends in the museum display regardless of the occasion, regardless of the conditions for the abuse of new technologies. Some digital media exhibits have no clear purpose for display, and are applied for applications, and all kinds of new media technologies are placed in the existing display. Instead, it destroys the clues and structure of the show. For example, the restoration of scenes in a museum in the Yangtze River Delta, using a whole glass wall as a medium, projecting illusory abstract light bands and other content, completely separated from the content and context of the display, so that the audience did not know what to say. The ideal display project should be closely integrated with the content and form to convey the content completely and accurately through digital media. However, in practical applications, it is often seen that exhibits whose form is almost irrelevant to content are often ported to a different display content. For example, the interactive ground screen projections that have been popular for a while appear in many museums in various appearances, and the content of the display is often unrelated, which is very far-fetched.

Good digital media presentation is a scientific and rigorous basic content combined with reasonable and well-founded imagination. Without the support of academic research and image 
materials, it is just unfounded and deductive, and even obvious errors. Not only can not achieve the content that you want to convey, it seriously damages the scientific and educational significance of the exhibition, and affects the public image of the museum. For example, some of the films in some museums are directly edited from movies and TV series. There is no academic research on relevant historical facts and details, which does not meet the scientific and accuracy requirements of museum cultural communication.

The equipment or content of the digital media exhibition is arranged in an inappropriate display environment, or is not well integrated into the exhibition hall environment, affecting the display effect, and is abrupt and blunt. For example, setting a phantom image in a bright exhibition environment requires a low illumination environment. The exhibitions set up modern equipment without artistic modeling in the ancient simulation scene; another: the dynamic facilities are stiff; the interactive equipment is difficult to operate; the viewing angle of the theater is not good; the subsystems in the exhibition are not coordinated; Raw sugar, lack of brightness, unclear picture quality, unsmooth playback, unnatural sound effects, etc., caused the actual display effect to not meet expectations.

\section{Digital Media Display Planning and Design Process}

According to the content of the overall exhibition outline of the museum and the purpose of dissemination, the feasibility evaluation of the multi-purpose theater was proposed. After determining the project, the theater is reasonably arranged to show the position on the streamline and the relationship between the content of the film and other parts of the show. In-depth analysis of the purpose of display communication, to clarify the general content of the multi-functional theater needs to be displayed, the display effect to be achieved. According to the future positioning and expectations of the museum, determine the size of the theater, the amount of funds invested, the length of the film, and the special effects that need to be considered in advance, so as to fix the building space requirements, such as building area, length and width, weight bearing, The design requirements for beams and columns structure, power supply, HVAC, water supply and drainage, etc. are submitted to the building design and construction side. In the design and construction of buildings, in addition to complying with the general cinema architectural design plan, the special requirements of the theater must also be considered, such as the implementation conditions of some environmental special effects. According to the display needs, the demonstration of cinema technology, according to the spatial pattern of the exhibition, the existing academic support materials, select the appropriate display program, basically determine which cinema technology to use to achieve, which environmental effects need to be used, on this basis Form the overall plan of the theater. It is also possible to temporarily determine the specific technology type (such as screen type, sound field type, etc.) and select an ideal bidding scheme to implement during the bidding process.

If the museum does not include a cinema project in the overall tender for the show, it will need to be tendered separately. At present, the companies engaged in the design and production of multi-functional cinemas in China are not well-balanced and lack the corresponding qualification standards. Choosing the right design and production units is a necessary condition for the smooth implementation of the project. Therefore, in the bidding process, we must comprehensively consider the bidder's bidding plan (hardware, software, film planning, comprehensive quotation), technical strength, after-sales service, success stories, and the type of cinema and film that we are good at, and choose the most suitable bidding plan. .

According to the established cinema construction plan, complete the hardware equipment selection analysis, software requirements analysis, and film segmentation script writing. (1) The selection analysis of hardware equipment includes the performance, parameters, space occupied by the equipment and the space requirements required to use the equipment, such as the brightness, separation rate, color, contrast, fuselage volume and effective projection distance of the projector. The material, shape, size, curvature, gain and diffuse reflection, acoustic characteristics of the screen; CPU frequency of the playback server, graphics acceleration card performance, hard disk 
speed and capacity, memory capacity and frequency, etc.; and sound system (including sound system) And sound absorption engineering), environmental special effects system, dynamic platform system, central control system and so on.

\section{Conclusion}

According to the characteristics of museum display and the advantages of digital media technology, this paper attempts to summarize the basic principles and requirements for the reasonable combination of the two. Taking the multi-functional theater as an example, the scientific process of constructing digital media display was analyzed. According to the various communication needs of digital media in the museum display, such as information processing, historical scene reconstruction, deductive historical stories, and enhanced audience experience, this paper attempts to use specific cases to illustrate the planning, design, implementation and technical requirements of the exhibition. . However, for the design of museum digital media exhibitions, "Buddha has no law", each exhibition has unique communication purposes and academic support materials. When designing the project, it is still necessary to carry out the project according to the actual situation. Design, the examples given in the text are for reference only. Although digital navigation is not a major component of museum display, it is still worthy of in-depth research and exploration as an important display assisting technology.

\section{Acknowledgment}

National Social Science Fund (18bzs095).

\section{References}

[1] Ma Yujing. Discussion on Digital Media Technology in Museum Exhibitions [J]. China Museum, 2015(4):89-95.

[2] Tian Wei. Application and Development of Digital Media Technology in Digital Museums [J]. Information and Computer, 2014(11): 130-130.

[3] Xiang Donghong, Wang Anxia. User Experience of Digital Media Technology in Museum Space Display [J]. Science \& Technology Information, 2017(25).

[4] Yan Wenzhen. Innovative Application of Digital Media Technology in Museum Design [J]. Research on Heritage and Protection, 2018(04):97-99.

[5] Zhang Chengliang. Analysis of Digital Media Technology in Museum Exhibitions [J]. China National Expo, 2016(9). 